BULLETIN Bulletin hispanique

HispaniquE Université Michel de Montaigne Bordeaux

$116-2$ | 2014

Référentialité/autoréférentialité dans le roman espagnol contemporain : bilan et perspectives

\title{
Entre el silencio y la confesión
}

intelectuales y artistas en Nocturno de Chile de Roberto Bolaño

\section{Félix Terrones}

\section{(2) OpenEdition \\ Journals}

\section{Édition électronique}

URL : http://journals.openedition.org/bulletinhispanique/3645

DOI : 10.4000/bulletinhispanique.3645

ISBN : 979-10-300-0156-3

ISSN : 1775-3821

Éditeur

Presses universitaires de Bordeaux

\section{Édition imprimée}

Date de publication : 1 décembre 2014

Pagination : 875-897

ISBN : 978-2-86781-963-6

ISSN : 0007-4640

Référence électronique

Félix Terrones, «Entre el silencio y la confesión », Bulletin hispanique [En ligne], 116-2 | 2014, mis en ligne le 01 décembre 2017, consulté le 02 mai 2019. URL : http://journals.openedition.org/

bulletinhispanique/3645; DOI : 10.4000/bulletinhispanique.3645 


\title{
Entre el silencio y la confesión : intelectuales y artistas en Nocturno de Chile de Roberto Bolaño
}

\author{
FÉLIX TERRONES \\ AMERIBER - Bordeaux Montaigne
}

Mis silencios son inmaculados. Que quede claro. Pero sobre todo que le quede claro a Dios. Lo demás es prescindible.

Dios no.

Nocturno de Chile, Roberto Bolaño

En nous attachant à la trajectoire romanesque du narrateur et protagoniste du roman "Nocturno de Chile ", nous chercherons à mettre en évidence les caractéristiques et les valeurs de ce qui est relaté à la première personne sous le registre de la confession. Ambigu et paradoxal, le récit de Urrutia Lacroix décline à de nombreux niveaux les traits spécifiques de l'homme de lettres.

Mots-clés : Nocturno de Chile, mémoire, confession, champ littéraire.

Deteniéndonos en la trayectoria novelesca del narrador protagonista en la novela "Nocturno de Chile", buscaremos resaltar las características y los valores de lo contado en primera persona bajo el registro de la confesión. Ambiguo y a la vez paradójico, el relato de Urrutia Lacroix declina a múltiples niveles los rasgos específicos del sujeto letrado.

Palabras claves: Nocturno de Chile, memoria, confesión, campo literario.

Taking the time to study the novelistic trajectory of the protagonist narrator in the novel "Nocturnal of Chile» by Roberto Bolaño, we will seek to bring out the characteristics and the values of what is related in the first person, under the register of confession. Ambiguous and at the same time paradoxical, the tale told by Urrutia Lacroix declines the characteristics of the man of letters on several levels.

keywords: Nocturno de Chile, memory, confession, litterary field. 
S ebastián Urrutia Lacroix, narrador y protagonista de la novela, plantea en la primera oración una tensión entre la palabra y la muerte: «Ahora me muero pero tengo muchas cosas que decir todavía» ${ }^{1}$. Consciente de su situación liminar, el narrador inaugura su relato subrayando su capacidad para seguir hablando (o escribiendo). El adverbio «todavía» añade un elemento particular a su enunciado pues si bien podemos entenderlo como la capacidad para contar más, también es posible interpretarlo en función del tiempo que le queda antes de caer en ese silencio que es la muerte. De ese modo, desde el inicio mismo de la novela, el lector descubre una homologación, subrepticia y oblicua, entre el hablar y el vivir. Frente al silencio que representa la cercanía de la muerte, la palabra se levanta y despliega como el reducto del recuerdo y la memoria para afirmar una trayectoria vital particular y emblemática.

Esta repentina necesidad de hablar no es espontánea ni gratuita, antes bien se ve motivada por la aparición de un individuo que el narrador denomina joven envejecido, una presencia fantasmal pero permanente en la novela ${ }^{2}$. Dicho joven envejecido actuará de desencadenante y agraviante del deseo y esfuerzo por hablar. El mismo Urrutia Lacroix se encarga de señalarlo cuando precisa : «estaba en paz conmigo mismo. Mudo y en paz. Pero de improviso surgieron las cosas. Ese joven envejecido es el culpable. Yo estaba en paz $^{3} »$. De ese modo, si el uso de la palabra se contrapone a la amenaza de la muerte, el empezar a hablar supone dejar el silencio, por lo tanto, abandonar el sosiego y la calma. Con todo, el objetivo lo justifica, es decir, el hacer frente a los agravios del joven envejecido ${ }^{4}$ quien parece haber difamado a Sebastián Urrutia Lacroix. La palabra emergería, por lo tanto, como un acto de justicia, valor y verdad para confrontar la invectiva, el insulto, la infamia.

Esfuerzo de la memoria y defensa cerrada contra una acusación, el ejercicio de la palabra oscila entre una y otra coordenada a lo largo de la novela. La manera cómo esta oscilación no se restringe exclusivamente al incipit del texto sino que constituye todo un programa estético da motivo para rastrear tanto sus declinaciones más singulares como el significado y los valores que ellas encubren. En este sentido, nos gustaría detenernos en la evolución (o el derrotero) del personaje narrador y protagonista para reflexionar acerca de la manera en que se concibe a sí mismo como individuo pero también actor social, lo que en su caso quiere decir como sacerdote y hombre de letras. Por eso, después de caracterizar la manera en que plantea el quehacer literario analizaremos, en un segundo momento, su inserción en el campo letrado de su sociedad para,

1. Roberto Bolaño, Nocturno de Chile, Barcelona, Anagrama, 2000, p. 11.

2. Ejemplo de las invectivas del joven envejecido: «De vez en cuando algunas de sus palabras me llegan con claridad. Insultos, qué otra cosa. ¿¿Maricón, dice? ¿Opusdeísta, dice? ¿ Opusdeísta maricón, dice? Luego mi cama da un giro y ya no lo oigo más. Qué agradable resulta no oír nada». Roberto Bolaño, op. cit., p. 70.

3. Ibid., p. 11.

4. Urrutia Lacroix decidirá hablar: «Pero aún tengo fuerzas para recordar y para responder a los agravios de ese joven envejecido que de pronto ha llegado a la puerta de mi casa y sin mediar provocación y venir a cuento me ha insultado». Ibíd., p. 12. 
finalmente, elucidar las declinaciones de su crisis en un país descompuesto por la dictadura militar a la cual se le da una relevancia particular dentro de la ficción novelesca. De esa manera, un último elemento de análisis será el lugar del creador y el crítico literario, y en última instancia de la misma literatura, en sociedades y periodos convulsos tales como los escogidos por Roberto Bolaño en una gran parte de sus novelas y que en Nocturno de Chile se presentan bajo rasgos perentorios pero al mismo tiempo ambivalentes que será conveniente resaltar e interrogar ${ }^{5}$.

\section{Retrato del artista en crítico: Urrutia Lacroix e H. Ibacache}

El narrador de la novela es un individuo que constantemente sugiere, plantea e incluso reivindica sus dobleces. Así lo hará por primera vez cuando poco después de empezado su monólogo-narración, como si se tratase de una entrada en escena, presenta su genealogía familiar:

Me llamo Sebastián Urrutia Lacroix. Soy chileno. Mis ancestros por parte de padre, eran originarios de las Vascongadas o del país Vasco o de Euskadi, como se dice hoy. Por parte de madre provengo de las dulces tierras de Francia, de una aldea cuyo nombre en español significa Hombre en tierra u Hombre a pie, mi francés en estas postreras horas, ya no es tan bueno como antes.

Curiosa la manera que Sebastián Urrutia Lacroix utiliza para explicar su nacionalidad. Si bien, el primer elemento biográfico que subraya es el ser "chileno», inmediatamente después decide explicar de qué regiones europeas vienen sus ancestros: Espańa y Francia. De esta manera, la condición de chileno pareciera ser marginada por los otros dos horizontes que precisa de manera minuciosa a su lector. En un continente, en un país, en el que un puñado de individuos es descendiente de extranjeros, Urrutia no sólo enfatiza su condición de hijo de migrantes sino que le da un valor particular a la hora de decir quién es, como si se tratase de recordar un lustre o un abolengo que lo distinguiría frente a los demás. Dicho sea de paso, el origen doble de Sebastián Urrutia Lacroix le llevará, a lo largo de su vida, a alternar estadías entre Europa y América latina, así como también a exhibir un conocimiento, generalmente prolijo y enciclopédico, de la producción literaria y letrada tanto europea como chilena.

5. Pensemos en un texto como La literatura nazi en América, colección de biografías ficticias que cuenta las vidas de escritores filonazis en diversos países latinoamericanos. Inevitablemente, la producción literaria de estos escritores vehiculará, de un modo o de otro, sus erráticas convicciones ideológico-políticas. Pensemos en otro ejemplo: la vastísima e intensa 2666, donde cuatro críticos buscan al escritor alemán de tenebroso pasado Benno von Archimboldi quien dejó su país para perderse en México, más precisamente, en Santa Teresa, ciudad a la cual está dedicada una sección del libro - La parte de los crímenes- en la cual abundan los irracionales, masivos y rituales asesinatos de mujeres. La creación literaria en la obra de Bolaño se encuentra constantemente vinculada con una dimensión maligna. In Roberto Bolańo, La literatura nazi en América, Barcelona: Seix Barral, 1996, 237 p. y Roberto Bolaño, 2666, Barcelona: Anagrama, 2004, 1125 p. 
De hecho, la dualidad que el narrador resalta de sus orígenes pareciera ser evocada y declinada de diversas maneras y a múltiples niveles a lo largo de su trayectoria vital. Así, cuando escoge su vocación decide ser, al mismo tiempo, sacerdote y hombre de letras: ambas coordenadas, parecen mezclarse y yuxtaponerse sin que por eso se confundan. Recordemos, por ejemplo, que cuando acude al fundo $L \grave{a}$-bas del crítico Farewell se presenta con sotana y no se quita nunca esa prenda de vestir ${ }^{6}$. La vocación religiosa y la artística parecen entrelazadas sin posibilidad de elección entre una u otra, como también ocurre al interior mismo de su faceta letrada. En efecto, como hombre de letras, Urrutia Lacroix tiene vocación poética pero también ambiciona ser un crítico literario. Entre la creación y la reflexión, el narrador decide escindir, al menos en términos onomásticos, su doble condición. De ese modo, escoge como nom de plume el de $\mathrm{H}$. Ibacache, feliz pseudónimo que, por un efecto de simetría fónica, duplica al comienzo y al final, la consonante «H»: «H ibac $\mathrm{H} »$.

No hay nada de original en esta decisión de escindir, ya desde el nivel onomástico, la labor literaria. De hecho, al escoger un pseudónimo que lo identifica y al mismo tiempo distingue de sus pares literarios, Urrutia Lacroix repite en su gesto al individuo que, desde su visita a $L \grave{a}-B a s$, se convertirá en su protector y ejemplo: el gran crítico literario Farewell (cuyos apellidos son González Lamarca ${ }^{8}$ ). El mismo Urrutia Lacroix recuerda el momento -medio solemne, medio esperpéntico- en el que recibió su «bautismo en el mundo de las letras» ${ }^{9}$ de parte del maestro:

(...) y cuando yo le dije, con la ingenuidad de un pajarillo, que deseaba ser crítico literario, que deseaba seguir la senda abierta por él, que nada había en la tierra que

6. «Sólo entonces me di cuenta, con un estremecimiento, de que aún llevaba la sotana con la que había emprendido el viaje. En mi confusión estaba seguro de habérmela quitado (la sotana) cuando subí a la habitación que Farewell había destinado para mí. Pero lo cierto es que sólo pensé en cambiarme y no me cambié y luego bajé a reunirme de nuevo con Farewell en el pabellón de caza». Ibid., p. 20.

7. Milagros Ezquerro y Karim Benmiloud han analizado con detenimiento y precisión los diversos significados, evidentes y sugeridos, del pseudónimo. Mientras que Milagros Ezquerro subraya el origen y el significado vascos del apellido, Karim Benmiloud desvela una construcción bilingüe (español-francés) : «iba caché», lo cual quiere decir que el personaje «transitaba escondido». En Milagros Ezquerro, "Sebastián Urrutia Lacroix alias H. Ibacache» in Les astres noirs de Roberto Bolaño, Karim Benmiloud y Raphaël Estève (eds.) Bordeaux: Presses Universitaires de Bordeaux, 2007, p. 33-39. Karim Benmiloud, "Sordel, Sordello, ¿qué Sordello?” Forme et fonction d'un leitmotiv dans Nocturne de Chile ", in La memoria de la dictadura, Fernando Moreno (ed.) Paris, Ellipses, 2006, p. 149-158. Me gustaría señalar que en este pseudónimo, tan rico en sentidos y significados, se subraya también (y una vez más) la tensión entre el silencio y la palabra pues la letra privilegiada o repetida es la «H», la misma que en el alfabeto castellano es conocida como la «muda» (pues no se pronuncia). Pese a su «mudez», la letra «H» gracias a su duplicación dentro del pseudónimo le entrega una substancia, una virtualidad, al nom de plume del personaje.

8. No es necesario subrayar que de este personaje no se transmiten los nombres de pila. Lo que verdaderamente importa del hombre de letras como Farewell es su pseudónimo y cuando se conoce su "verdadera identidad » solamente se transmiten sus apellidos, es decir, su pertenencia a una tribu, una familia.

9. Ibid., p. 34. 
colmara más mis deseos que leer y expresar en voz alta, con buena prosa, el resultado de mis lecturas, ah, cuando le dije eso Farewell sonrió y me puso la mano en el hombro (una mano que pesaba tanto o más que si estuviera ornada por un guantelete de hierro) y buscó mis ojos y dijo que la senda no era fácil. En este país de bárbaros, dijo, ese camino no es de rosas. En este país de dueños de fundo, dijo, la literatura es una rareza y carece de mérito el saber leer. Y como yo, por timidez, nada le respondiera, me preguntó acercando su rostro al mío si algo me había molestado u ofendido ${ }^{10}$.

En la cita, estamos una vez más frente a otro desdoblamiento: la memoria del individuo que se recuerda a sí mismo es la misma que transmite la concepción que el «famoso» ${ }^{11}$ y «mayor crítico de Chile»" tiene del quehacer literario. Advirtamos la camaradería que existe entre uno y otro personaje, manifiesta mediante el gesto de Farewell de colocarle la mano en el hombro. Con todo, la imagen que viene inmediatamente después entre paréntesis -la del guantelete de hierro ${ }^{13}$ - subraya la distancia y el respeto entre uno y otro individuo. Reconocimiento de un talento, por un lado (el de Farewell), y sumisión, por el otro (el de Urrutia Lacroix), ambos personajes, encarnan en esa escena de la novela una verdadera revelación entregada al joven clérigo, no de la palabra divina, sino de un profeta de las letras.

La revelación no es otra que la de una paradoja expresada claramente por Farewell; a saber, la falta de lectores para quien decide ser un crítico literario. El amante de la literatura que escoge ser un crítico, toma un "camino» difícil por culpa de la ignorancia de la sociedad chilena. De hecho el adjetivo que Farewell utiliza para calificar a los chilenos se encuentra particularmente connotado en las letras latinoamericanas: «bárbaro». En efecto, desde el Facundo ${ }^{14}$ de Domingo Faustino Sarmiento se utiliza ese término para caracterizar una tensión constitutiva de nuestras sociedades, aquella que opone la "civilización» a la «barbarie». Así, de manera tácita, Farewell manifiesta una distancia entre el sujeto letrado chileno y el resto de la nación. Al hacer esto, se ubica

10. Ibid., p. 14

11. Ibid., p. 13.

12. Ibid., p. 15.

13. Si coordinamos dos de las imágenes de la cita con otros elementos textuales que aparecen posteriormente entonces las comparaciones adquieren un nuevo valor. Si, por un lado, Urrutia Lacroix es un "pajarillo " y, por el otro, la mano de Farewell es tan pesada como un " guantelete de hierro " entonces resulta evidente el vínculo con el periplo europeo de Urrutia Lacroix, contado más adelante (p. 83-95), para conocer a los sacerdotes que crían aves de rapiña con el objetivo de deshacerse de las palomas. Hacia el final del relato dedicado al periplo europeo de Urrutia Lacroix este mismo reflexiona del modo siguiente « tal vez no es una buena idea esto de los halcones porque aunque preservan a la iglesia del efecto corrosivo y a la larga destructor de las cagadas de la paloma, no había que olvidar que las palomas eran como el símbolo terrenal del Espíritu Santo, ¿verdad? » Ibíd., p. 90. Convertido en el ave cazadora de Farewell, Urrutia Lacroix no sólo lo reconoce como amo sino que se inserta, pasiva y acríticamente, en una dinámica que desnaturaliza lo que debería ser el lugar de la literatura en una sociedad tal y como se revela al final de la novela. En lugar de ser un ejercicio de crítica al poder (o los poderes) establecido es una herramienta de justificación y dominio ideológicos. Volveremos sobre este punto más adelante.

14. Domingo Faustino Sarmiento, Facundo: civilización y barbarie, Madrid: Cátedra, 1990, $457 \mathrm{p}$. 
sintomáticamente del lado de los «civilizados» y reivindica para sí una actividad difícil -«ese camino no es de rosas»- que, al mismo tiempo, es susceptible de aislarlo y distinguirlo entre los demás actores sociales ${ }^{15}$.

Basta advertir el tipo de actividades que se realizan en el fundo de Farewell para profundizar de mejor modo en la manera cómo éste concibe lo "civilizado». En $L \grave{a}-b a s$, nombre que es un verdadero homenaje a la novela francesa ${ }^{16}$, se habla constantemente de literatura clásica europea, en particular italiana. Así, desfilan nombres como Iacopone da Todi, Giacomo da Verona, Pietro de Bescapé, Bonvensin de la Riva, el mismo Dante y el inevitable Sordello (que dará pretexto al estribillo tantas veces repetido en la novela). Por lo demás, las lecturas que Urrutia Lacroix realiza durante su estadía en $L \grave{a}$-bas son bastante significativas: Historia de la Literatura Italiana de los siglos XIII, XIV y $X V^{17}$. Lecturas más contemporáneas sólo se pueden permitir en función de su relación con los autores clásicos y canónicos admirados. De ese modo, por ejemplo, se dice que el mismísimo Ezra Pound escribió acerca del ya aludido Sordello ${ }^{18}$. Por si no fuera suficiente con la fogosa y desesperada pasión por la literatura europea, incluso las nubes que cruzan el cielo poseen una dimensión alternativa, no son nubes cualesquiera sino que son «nubes baudelerianas»" ${ }^{19}$. Si Farewell significa en español «adiós», Là-bas quiere decir «allá lejos»: una y otra denominación subrayan la distancia cronológica, espacial y cultural entre aquello que se elige admirar y aquello que se mantiene a distancia, por bajo, ignominioso, incivilizado. La palabra evoca, a nivel de pseudónimos y topónimos pero también de referentes culturales (todos los hombres de letras citados convertidos en faire-valoir) una realidad otra, ajena y distante, por eso mismo codiciada por esos nostálgicos hombres cultos varados para desgracia suya en el lejano e ilegible Chile ${ }^{20}$.

15. No deja de ser significativo que, lo mismo que Sebastián Urrutia Lacroix, Sarmiento haya sido un individuo fascinado por la cultura europea, a la que le dedicó al menos un libro: «Viajes». Según lo afirma Marcel Montserrat, «Viajes» es un texto que mezcla el testimonio de un viaje considerado iniciático con el inicio de un desengaño, el desengaño de la decepción política que Sarmiento vive durante su periplo europeo. De ahí que el intelectual argentino haya terminado decantándose por la joven república democrática americana como parangón de sistema social. Pese al desencanto que le produce Europa es imposible no reconocer en Sarmiento la misma fascinación que tiene Urrutia Lacroix frente a países considerados como desarrollados. In Marcelo Montserrat, Hacia las fuentes del entusiasmo político (el viaje iniciático de Sarmiento), Viajes, ed. Javier Fernández, Madrid: ALLCA, 1993, p. 1027-1032.

16. Là-bas es el título de la novela (1891) de Joris-Karl Huysmans (1848-1907) en la cual el héroe, Durtal, cansado de su entorno y tiempo busca un refugio en la Edad Media francesa, en general, y en un personaje histórico, en particular, Gilles de Rais (1404-1440), figura fascinante que también ha inspirado a escritores como Michel Tournier y Georges Bataille.

17. Ibid., p. 28.

18. Ibid., p. 27.

19. Ibid., p. 34.

20. Incluso en sus gestos y manera de vestir Farewell subraya lo europeo y, en ello, la bonanza, el cosmopolitismo, la adscripción a una alta burguesía ilustrada : «(...) y allí estaba Farewell, alto, un metro ochenta aunque a mí me pareció de dos metros, vestido con un terno gris de buen paño inglés, zapatos hechos a mano, corbata de seda, camisa blanca impoluta como mi propia ilusión, 
Por lo demás, en $L \grave{a}$-bas se organizan veladas literarias con rasgos únicos donde lo que abunda no es precisamente la austeridad pues, a juzgar por el menú de la velada, se come copiosamente: «ensalada a la chilena, piezas de caza acompañadas de una salsa bearnesa» junto con un "congrio al horno ${ }^{21}$ ». Se trata de un banquete que reúne, por un lado, a los celebrantes y refuerza, por el otro, la capacidad de Farewell para gastar y despilfarrar en armonía con las características del festín rescatadas por Bakhtine: "Cette rencontre avec le monde dans l'absorption de nourriture était joyeuse et triomphante. L'homme triomphait du monde, l'avalait au lieu d'être avalé par lui ; la frontière entre l'homme et le monde seffaçait dans un sens qui lui était favorablè ${ }^{22}$. Por medio del banquete, los hombres de letras se evaden de la realidad circundante, juzgada mezquina, pobre y brutal, para entregarse, entre los muros de Là-bas, a la sensación de infinito. En este contexto, Farewell adquiere una característica adicional ante los ojos de Urrutia Lacroix : «la figura homérica de Farewell me observaba con las manos en jarra» ${ }^{23}$. Ya no se trata del dueño de un fundo o del más importante crítico literario chileno sino del mismísimo poeta griego, cimiento de la literatura occidental. Convertido en parangón homérico, el personaje termina de adquirir los rasgos que fascinan al sacerdote y crítico en ciernes. Poco importa si con ellos están sentados figuras de la talla de Pablo Neruda junto con otros poetas: la literatura en la casa de Farewell no es encarnada por los creadores consagrados ni los que están por consagrarse sino por aquellos que ejercen la crítica literaria, convencidos de que su mirada penetrante descubre, funda y aclara el mundo ${ }^{24}$. En medio del banquete, el jolgorio y la celebración hedonistas, la imagen de Farewell adquiere contornos legendarios y arquetípicos.

Amantes de las letras en un fundo afrancesado, cortesanos de una corte sin rey pero con árbitro de las formas y el buen gusto, quienes se integran a las veladas en el fundo lo hacen sin tener la menor idea de qué es lo que ocurre "afuera» de éste. No ocurre lo mismo, sin embargo, con Urrutia Lacroix quien franquea las fronteras de $L \grave{a}$-bas y se aventura allá por donde están «unos

mancuernas de oro, y un alfiler en donde distinguí unos signos que no quise interpretar pero cuyo significado no se me escapó en modo alguno (...)». Ibid., p. 13.

21. Ibid., p. 25.

22. Mikhail Bakhtine, L'ouvre de François Rabelais et la culture populaire au Moyen Âge et sous la Renaissance, Paris: Gallimard, 1970, p. 280. Dicho sea de paso, más tarde una fiesta es evocada por Urrutia Lacroix: «Otras veces discernía a un grupo de figuras cogidas por la cintura, como si bailaran la conga, desplazarse a lo largo y ancho de un salón cuyas paredes estaban atiborradas de cuadros. Baile, padre, me decía alguien a quien no veía (...) entonces yo distinguía a Farewell entre los danzantes, a Farewell que asía por la cintura a una señora de la mejor sociedad chilena de aquellos años, una señora de apellido vasco que desgraciadamente he olvidado». Roberto Bolaño, op. cit., p. 35.

23. Ibid., p. 25.

24. Resulta paradójico en este sentido que, convertido en Homero, Farewell observe al sacerdote pues, como sabemos, la tradición señala que el poeta griego era ciego. ¿¿Eror de Urrutia Lacroix o ironía involuntaria? Como precisaremos más adelante, existe un sentido oculto en la imagen que utiliza y la verdadera naturaleza del quehacer literario en Chile. 
huertos que parecían dejados de la mano de Dios» ${ }^{25}$, según el lenguaje bíblico que utiliza a cada oportunidad que se le presenta. Una vez afuera de Là-bas, extravía el camino y, perdido, confundido, cruza un puñado de seres bastante diferentes de los que frecuenta en la casa de Farewell. A continuación el fragmento que detalla, siempre bajo la perspectiva del sacerdote, su encuentro con esos individuos:

Y el hombre que había acompañado a las mujeres a mi encuentro, aquel cuya zarpa me había sujetado de la muñeca, permaneció sin moverse, apartado unos cuantos metros de las mujeres y de mí, pero giró la cabeza y siguió con la mirada el derrotero de sus compañeros, como si de pronto le interesara sobremanera aquello que los otros hacían o veían, aguzando la mirada para no perderse ni un solo detalle. Recuerdo que me fijé en su rostro. Recuerdo que bebí su rostro hasta la última gota intentando dilucidar el carácter, la psicología de semejante individuo. Lo único que queda de él en mi memoria, sin embargo es el recuerdo de su fealdad. Era feo y tenía el cuello extremadamente corto. En realidad, todos eran feos. Las campesinas eran feas y sus palabras incoherentes. Los campesinos que se alejaban eran feos y su singladura en zigzag incoherente. Que Dios me perdone y los perdone. Almas perdidas en el desierto. Les di la espalda y me marchée ${ }^{26}$.

El episodio en casa de Farewell reúne los grandes motivos del texto entero y al mismo tiempo anticipa los eventos desarrollados en otro espacio habitado, ya no el fundo de un gamonal viejo cuño, sino en la casa de una aspirante a escritora y madre de familia, María Canales. En este caso, nos encontramos frente a una tensión explícita pero significativa entre dos coordenadas espaciales: el «adentro» y el «afuera ${ }^{27}$. Si «adentro» seres civilizados se reúnen para discutir acerca de literatura, y cualquiera de las actividades edificantes que el hombre

\section{Ibid., p. 29.}

26. Ibid., p. 32-33.

27. Los espacios textuales no deben ser entendidos como un simple decorado en las ficciones; al contrario, ellos poseen un valor y un significados que es necesario subrayar debido a la capacidad que tienen para indicar atmósferas y enriquecer, infundiéndoles complejidad las intrigas, dar cuenta asimismo de los diversos puntos de vista. En este sentido Jean Weisgerber, desde una perspectiva estructuralista afirma que : "Composé de mots, l'espace romanesque comprend tous les sentiments et concepts spatiaux que le langage est capable d'exprimer, mais, en se les annexant, il en modifie automatiquement le statut. Et c'est là, précisément, ce que tel ou tel écrivain - les réalistes entre autres - voudrait faire oublier. "Jean Weisgerber, L'espace romanesque, Lausanne : Éditions l'Âge d'homme, 1978, p. 11. Después, el mismo Weisgerber recuerda que a la hora de analizar un espacio literario, cuya materialidad reside y se fundamenta en las palabras, debemos tener en cuenta lo siguiente : "différentes catégories concernant : la forme (cercle/droite), le mouvement qui introduit l'idée de temps (statique/dynamique, expansion/ contraction, attraction/répulsion, directions horizontale ou verticale), la communication (ouvert/ fermé, dedans/dehors), la continuité (continu/discontinu), le groupe ou l'ensemble (union (conjonction)/séparation (disjonction), genre (espèce)/individu, privé/public, ville/campagne) auxquels doivent s'adjoindre le nombre (pluralité/unicité, foule/solitude, habité/désert, civilisé/ sauvage) et l'éclairage (clair/obscur, blanc/noir). L'espace romanesque, on le verra, repose en effet sur une multitude d'impressions auditives et visuelles, d'où la mise en question, bien légitime, de la validité des phénomènes sensibles tels que vêtements (être/paraitre), couleurs et autres qualités d'objets (vide/plein, étroit/large, mince/gros, fluide/solide). "Ibid., p. 18. 
conoce y valora, «afuera» ocurre algo completamente diferente: basta penetrar en el inhóspito bosque que rodea al fundo para encontrar a un grupo de seres en las antípodas de aquellos que se abrigan en $L \grave{a}$-bas. El anónimo hombre con el que interactúa Urrutia Lacroix es caracterizado de modo tal que se le niega cualquier rasgo de humanidad (por ejemplo, en lugar de tener una mano posee una "zarpa ${ }^{28}$ ). Lo mismo ocurre con las mujeres que lo acompańan, quienes se expresan de manera caótica: «sus palabras (eran) incoherentes». Bestias sin auténtico lenguaje, estos "otros» chilenos poseen un rasgo que para el esteta Urrutia Lacroix salta a la vista: su fealdad. Frente a esta «barbarie horrible» encarnada por ese puñado de seres, Urrutia Lacroix no puede reaccionar de otro modo que dándoles la espalda, actuar como si no existiesen (pese a que indefectiblemente se encuentran ahí), antes de regresar al fundo para protegerse y procurar olvidar tan desagradable anécdota.

No es un azar que Urrutia Lacroix se refiera en la cita precedente a la manera de andar de los campesinos como «singladura» de «andar incoherente». Según el DRAE, «singladura» es un término marítimo que significa: «distancia recorrida por una nave» ${ }^{29}$. Se trata de una comparación nada inocente en el texto. Más adelante, cuando Urrutia Lacroix manifiesta la manera cómo evolucionan sus dos "personalidades» literarias utiliza una vez más una imagen marítima:

\footnotetext{
Y poco a poco $\mathrm{H}$. Ibacache fue siendo más conocido que Sebastián Urrutia Lacroix, para mi sorpresa y también para mi satisfacción, pues Urrutia Lacroix planeaba una obra poética para el futuro, una obra de ambición canónica que iba a cristalizar únicamente con el paso de los años, en una métrica que ya nadie en Chile practicaba, ¡qué digo!, que nunca nadie jamás había practicado en Chile, mientras Ibacache leía y explicaba en voz alta sus lecturas tal como antes lo había hecho Farewell, en un esfuerzo dilucidador de nuestra literatura, en un esfuerzo razonable, en un esfuerzo civilizador, en un esfuerzo de tono comedido y conciliador, como un humilde faro en la costa de la muerte ${ }^{30}$.
}

El compromiso del crítico literario no es otro que arrojar un haz de luz lo suficientemente penetrante sobre la literatura como para que esta termine convertida en factor de civilización. Gracias al conocimiento que ellos lleguen a detectar, formular y transmitir, los lectores saldrían de la penumbra para elevarse a la trascendencia y redimirse. Desde luego, si se trata de un esfuerzo civilizador es porque se concibe, tácitamente, una ciudadanía a la cual guiar; con todo, los ciudadanos parecen distinguirse, maniquea y tendenciosamente, en dos tipos: aquellos que, como los campesinos indios, navegan de manera errática en la oscuridad y aquellos que, como Urrutia Lacroix, saben remar hasta llegar a Là-bas, el faro de Farewell. Entre uno y otro tipo de gente no

28. Si consideramos la definición de «zarpa " que da el DRAE entonces descubrimos que estamos frente a una animalización del individuo. "Zarpa " : "Mano de ciertos animales cuyos dedos no se mueven con independencia unos de otros, como en el león y el tigre. » En http:// buscon.rae.es/draeI/SrvltConsulta?TIPO_BUS=3\&LEMA=zarpa

29. http://buscon.rae.es/draeI/SrvltConsulta?TIPO_BUS=3\&LEMA=zingladura

30. Ibid., p. 36-37. 
existiría punto intermedio ni posibilidad de evasión; por lo tanto, todos aquellos condenados a quedarse "afuera» de $L \grave{a}$-bas son también quienes no tienen acceso a la ciudadanía en los términos formulados por el sacerdote: el ejercicio de las letras como medio de reconocimiento y exclusión social.

Subrayando su labor social, con el aquí y el ahora, Urrutia Lacroix deja para mañana la labor poética. En otras palabras, se hace cada vez más H. Ibacache. Personaje de dobleces infinitas, el sacerdote del Opus Dei conoce un verdadero rito de iniciación en el fundo $L \grave{a}$-bas que imprime en él una concepción particular del horizonte literario, así como del lugar y la función de la literatura en una sociedad: la literatura es un ejercicio elegante alejado de la barbarie de una sociedad como la chilena. Sin embargo, de momento tenemos una percepción bastante incompleta de la trayectoria de este personaje pues todavía no hemos visto la manera cómo el protagonista interactúa con la literatura de su sociedad y época. Toca ver, por eso, la manera en que Urrutia Lacroix se adscribe al quehacer literario -el campo letrado, por utilizar los términos de Pierre Bourdieu ${ }^{31}$ - que lo acoge y le da sentido.

\section{Afinidades ELECTIVAS: INTELECTUALES, ARTISTAS Y EL PODER}

En Nocturno de Chile, el sujeto letrado se somete a una relación binaria y horizontal con la institución literaria encarnada por Farewell: «arriba» se encuentra el crítico que brilla e ilumina desde su lugar privilegiado, «abajo» el aprendiz letraherido que anhela ascender, por medio de la estrategia zalamera y la progresiva acumulación de capital sociocultural, al cielo de los intelectuales $y$ artistas. Se trata de un vínculo que encarna tanto la mutua necesidad de reconocimiento (la del discípulo y del amo) como una concepción endogámica de la actividad literaria y letrada en la sociedad representada. Los dos pertenecen a la misma clase social y cultural razón por la cual, pese a sus diferencias generacionales, podemos decir que existe una continuidad entre ambos que asegura la perpetuación de sus prerrogativas de casta y también de aquello que juzgan como «bello»: los textos de épocas y regiones remotas a los cuales se acude para aislarse del ruido y el caos del mundo contemporáneo y ruin.

Sin embargo, H. Ibacache se inserta en toda una red de relaciones «profesionales» dentro de Santiago. Esta red de relaciones, antes «horizontal» que «vertical», enriquecerá todavía más las complejas significaciones que el texto le atribuye al lugar social del sujeto letrado. En este sentido asistimos a un nuevo desdoblamiento del narrador. Pese a que como lector se defina antes que nada como consumidor de bienes y productos culturales que lo insertan en una posición social elevada, por clásica y europeizante, como crítico tendrá que leer otro tipo de textos, menos clásicos y, por eso mismo, más actuales y cercanos.

31. Pierre Bourdieu, Les règles de l'art : genèse et structure du champ littéraire, Paris : Seuil, 1998, 567 p. 
Son los textos producidos en su tiempo por autores de su época y sociedad, tal y como él mismo lo precisa con detalle:

Por aquella época empecé a trabajar en la Universidad Católica. Por aquella época comencé a publicar mis primeros poemas, mis primeros poemas y luego mis primeras críticas de libros, mis apuntes de la vida literaria en Santiago. Me apoyo en un codo, estiro el cuello y recuerdo. Enrique Lihn, el más brillante de su generación, Giacone, Uribe Arce, Jorge Tellier, Efraín Barquero, Delia Domínguez, Carlos de Rokha, la juventud dorada. Todos bajo el influjo de Neruda salvo unos pocos que cayeron bajo el influjo o más bien el magisterio de Nicanor Parra. Y recuerdo también a Rosamel del Valle. Lo conocí, claro. Hice críticas de todos ellos: de Rosamel, de Díaz Casanueva, de Braulio Arenas y de sus compañeros de la Mandrágora, de Tellier y de los jóvenes poetas que venían del sur lluvioso, de los narradores del cincuenta, de Donoso, de Edwards, de Lafourcade. Todos buenas personas, todos espléndidos escritores. De Gonzalo Rojas, de Anguita. Hice críticas de Manuel Rojas y hablé de Juan Emar y de María Luisa Bombal y de Marta Brunet. Y firmé estudios y exégesis de Blest Gana y Augusto D’Halmar y Salvador Reyes. [...] Y entonces adopté el nombre de H. Ibacache ${ }^{32}$.

Los lectores de Bolaño reconocerán en la lista precedente una modalidad -la enumeración- típica del estilo del escritor chileno ${ }^{33}$. Se trata de un verdadero catálogo de la literatura chilena de los siglos XIX y XX, larguísimo inventario de creadores en el cual se encuentran escritores de todos los niveles sociales y posturas políticas imaginables. Parece, sin embargo, que a nivel estético los polos de atracción son dos: Pablo Neruda y Nicanor Parra. En el catálogo del crítico, alrededor de las dos figuras tutelares de la poesía chilena se ubican y distinguen, como electrones en la órbita de dos núcleos, los otros creadores literarios. El crítico que es $\mathrm{H}$. Ibacache advierte esta división del mundo letrado - ¿quién más podría hacerlo, si no es aquel que ha hecho de la dualidad su rasgo consubstancial?- pero lo hace con el objetivo de trascenderla. Poco importa si ambos poetas (Neruda y Parra) parecen ubicarse en las antípodas el uno del otro, cuando la mirada del crítico los reúne con su disciplinada clarividencia. Si «leer» es arrojar una luz entre las tinieblas, entonces H.Ibacache buscará penetrar con su mirada en lo más profundo del quehacer literario para encontrar una unidad en la diversidad. De este modo, mediante la crítica literaria, $\mathrm{H}$. Ibacache continuaría el trabajo de Farewell quien no solamente es "producido» por el tipo de lecturas que reivindica sino que al mismo tiempo "produce» un saber literario para sus conciudadanos. Este carácter activo de su ejercicio crítico será reivindicado poco después por él mismo cuando afirma lo siguiente con respecto a su labor: «Escribí críticas. Escribí poemas. Descubrí poetas. Los alabé. Exorcicé naufragios» ${ }^{34}$. El crítico frente a su época y a su tiempo ejerce

32. Ibid., p. 36.

33. Bernard Dupriez define del siguiente modo la enumeración : "Passer en revue toutes les manières, toutes les circonstances, toutes les parties". Más adelante, vincula a la "enumeración " con la "amplificación": "L'énumération est un mode d'amplification particulièrement bien venu car il passe de l'abstrait au concret, du général au particulier». Bernard Dupriez, Gradus, les procédés littéraires, Paris : 10/18, 1984, p. 185-186.

34. Ibid., p. 72. 
una labor de archivista pues escoge lo que considera debe perpetuarse y al mismo tiempo rescata del olvido lo que juzga inoportuno o injusto.

Cabe destacar un elemento que por «insignificante» hasta ahora no ha sido subrayado, Si H. Ibacache da cuenta de poemarios y novelas que leyó durante ese entonces ¿por qué se dedica a enumerar autores en lugar de hablar de libros? Lo que le interesa, contrariamente a lo que manifiesta, no es tanto evocar las lecturas que lo marcaron como subrayar subrepticiamente su lugar en la escena letrada de Santiago. De ahí que, por ejemplo, cuando se trate de Pablo Neruda afirme lo siguiente: «Una historia como ésta seguro que no la tiene el joven envejecido. Él no conoció a Neruda. Él no conoció a ningún gran escritor en condiciones tan esenciales como las que acabo de recordar ${ }^{35}$. Lo verdaderamente importante en la literatura no es tanto lo que se ha leído ni la experiencia de la lectura como a quién se ha conocido: mientras más escritores se haya frecuentado, más elevado e importante resulta el individuo a ojos de los demás. En perfecta consonancia con su concepción de la lectura, $\mathrm{H}$. Ibacache hace de la crítica literaria un medio para afianzar su prestigio social y su influencia de corte patriarcal ${ }^{36}$. Aquellos escritores y poetas que desearían ser reconocidos como tales en la sociedad santiaguina deberían, por lo tanto, granjearse la simpatía del sacerdote crítico. Como lo veremos más adelante, esta voluntad o necesidad de reconocimiento está, dentro de la novela, lejos de encontrarse despojada de repercusiones éticas o morales.

No obstante, ni siquiera el reconocimiento y el prestigio que lentamente adquiere le valen una situación tranquila o agradable, como él mismo lo precisa en un momento crucial de su relato-confesión:

El comienzo de una carrera brillante. Pero no todo fue tan fácil. A la larga hasta rezar aburre. (...) Fui probablemente el miembro del Opus Dei más liberal de la república. (...) Y eso producía no sólo desaliento en mi alma sino también aburrimiento, o tal vez el desaliento comenzó a devenir aburrimiento, cualquiera sabe, lo cierto es que hubo una época de calles amarillas y de cielos azules y luminosos y de profundo aburrimiento en que cesó mi actividad de poeta o mejor dicho mi actividad de poeta fue objeto de una mutación peligrosa, pues lo que se dice escribir, seguía escribiendo, pero poemas llenos de insultos y blasfemias y cosas peores que tenía el buen sentido de destruir apenas amanecía, sin mostrárselos a nadie, aunque entonces muchos se hubieran sentido honrados con tal distinción, poemas cuyo sentido último o lo que yo creía ver en ellos como sentido último, me sumían en una perplejidad y conmoción que duraban todo el día. Y ese estado de perplejidad y conmoción coexisitía con un estado de aburrimiento y abatamiento. (...) Fue por aquellos días que conocí al señor Odeim y al señor Oido ${ }^{37}$.

35. Ibid., p. 23-24.

36. Por lo demás, resulta sintomático que de los veinticinco escritores citados sólo aparezca el nombre de tres mujeres : usos y abusos de una sociedad donde lo femenino no parece tener un lugar igual de importante como lo masculino.

37. Ibid., p. 72, 73,74. 
A juzgar por lo que H.Ibacache transmite, el contacto constante y permanente con la producción literaria que le es contemporánea termina tergiversando la naturaleza del sacerdote. «Desaliento» $\mathrm{y}$ «aburrimiento» son los dos sentimientos que, según su testimonio, se abaten sobre él para pervertirlo de manera inaudita y alarmante. Incluso su escritura poética conoce una metamorfosis al pasar de ser una «obra de ambición canónica que iba a cristalizar únicamente con el paso de los años, en una métrica que ya nadie en Chile practicaba ${ }^{38}$, como él mismo lo seńaló poco antes, a "poemas llenos de insultos y blasfemias». Ya no se trata de estar enfrentado a lo considerado horrible, como los campesinos en Là-bas, sino de descubrir en sí mismo la semilla de aquello mismo que tanto le repele y atemoriza: por primera vez, H.Ibacache se encuentra delante de un horror del cual él es el autor. Con todo, felizmente para él, la caída verbal del esteticismo a la grosería tiene lugar en la soledad de la noche, lejos de los ojos de testigos. Por eso, del mismo modo en que dio la espalda a los campesinos, buscará ignorar sus faltas destruyendo lo que escribe. El crítico estético rehúye la opinión que los demás pueden emitir acerca de él, comportándose, antes que como un árbitro, como un dictador que desaparece cuanto es susceptible de desestabilizar su lugar preponderante.

Este acercamiento entre el crítico literario y el dictador será efectivo poco más tarde en la novela gracias a la aparición, oportuna y providencial, de los señores Odeim y Oido. En un artículo dedicado a estos dos personajes, Karim Benmiloud analiza la manera en la que ambos se inscriben dentro del circuito de dobles que plantea la novela. Así, según el crítico francés, una lectura de orden simbólico sugiere que ambos «figuran sentimientos que alberga el mismo narrador ${ }^{39}$, los sentimientos que sus nombres anagramáticos sugieren, es decir «Miedo» y «Odio». De ese modo, siguiendo la pista de lectura propuesta por Benmiloud, los desdoblamientos no sólo se restringirían a las elecciones y la trayectoria de Urrutia Lacroix sino que se ramifican a lo largo del texto entero ${ }^{40}$. En esta ocasión, el señor Odeim y el señor Oido surgen para arrancar al sacerdote de su abatimiento y modorra, entregarle una misión que lo anime en pos de un objetivo. De ese modo, gracias a las gestiones de ambos personajes, termina dejando Santiago para buscar la luz del continente europeo, embarcado en una misión que a su manera, grotesca y bufona, le permite continuar la comedia de

38. Ibid., p. 37.

39. Karim Benmiloud, "Odeim y Oido en Nocturno de Chile de Roberto Bolaño", Aisthesis (Revista Chilena de Investigaciones Estéticas), $\mathrm{n}^{\circ}$ 48, Santiago de Chile, Pontificia Universidad Católica de Chile, dic. 2010, p. 241. Por otro lado, como muy pertinentemente recuerda Fernando Moreno, «otros personajes presentes en el discurso del (sic) Ibacache pueden también considerarse como manifestaciones o variantes de dobles del protagonista (el tantas veces evocado "Sordello", el hijo de María Canales -el niño Sebastián-, a quien se refiere como su homónimo, por ejemplo)». In Fernando Moreno, "Rara avis : Nocturno de Chile », en La memoria de la dictadura, Fernando Moreno (ed.), Paris: Ellipse, 2006, p. 162.

40. En sus orígenes mismos ellos repiten los dobleces de Urrutia Lacroix : «¿Sabe de dónde proviene Oido? No tengo idea dije yo. Aventure un lugar, dijo él. ¿¿De Albania? Frío, frío, dijo él. No tengo idea, dije yo. De Finlandia, dijo él. Es un nombre mitad finlandés y mitad lituano.» Ibid., p. 79. 
la «civilización» contra la «barbarie»: conservar los monumentos católicos de las heces destructoras ${ }^{41}$.

No obstante, no es la única misión que los señores Odeim y Oido le asignan al sacerdote $\mathrm{H}$. Ibacache. Poco después de su regreso a Chile, durante los sucesos cuando determinaron el homicidio de Salvador Allende, Urrutia Lacroix tiene una crisis similar a la ya vista: «Mi poesía siempre había sido, para decirle en una palabra apolínea, y lo que ahora me salía era más bien, por llamarlo tentativamente de algún modo, dionisíaco. Pero en realidad no era poesía dionisíaca. Tampoco demoníaca. Era rabiosa $»^{42}$. Cuando el quehacer poético de Urrutia Lacroix amenaza con dejar el camino del esteticismo para introducirse por el sendero de la rabia y el dolor, que existen en él pero que se niega a liberar, es que por segunda vez aparecen los señores Odeim y Oido. Esta vez no se trata de una aparición orientada a reforzar, de un modo u otro, su pertenencia a la Iglesia sino su lugar y actividad en tanto agente cultural. En un momento particular en la historia chilena, ellos acuden a $\mathrm{H}$. Ibacache para proponerle una misión que no por inaudita deja de ser espinosa:

Somos portadores de una propuesta muy delicada, dijo el señor Odeim. Asentí con la cabeza y no dije nada. (...) Un servicio que se realiza en la oscuridad y la mudez, lejos del fulgor de las medallas, añadió. (...) ¿Y en qué consiste ese trabajo tan delicado?, dije. En darles unas cuantas clases de marxismo, no muchas, lo suficiente para que se hagan una idea, a unos caballeros a quienes todos los chilenos les debemos mucho, dijo el señor Odeim acercando su cabeza a la mía y echándome sobre la nariz una vaharada de cloaca.(...) ¿Quiénes son mis alumnos?, dije. El general Pinochet, dijo el señor Oido. Tragué aire. ¿̇Y quién más? El general Leigh, el almirante Merino y el general Mendoza, pues, ¿quiénes otros?, dijo bajando la voz el seńor Odeim. Tengo que prepararme, dije, no es asunto que pueda tomarse a la ligera. (...) Después el señor Odeim habló de mis honorarios ${ }^{43}$.

Como se deduce de los adjetivos y las fórmulas que utiliza el narrador -«delicada», «oscuridad», «mudez», «lejos del fulgor»-, el intercambio entre los tres individuos se realiza bajo el signo de la discreción y el silencio. Antes de

41. Misión en la cual muchos críticos han creído detectar una alegoría de las luchas intestinas entre dos facciones al interior de la Iglesia: la conservadora (emblematizada por los halcones) y los progresistas (las palomas). Al respecto, el crítico Pablo Berchenko afirma lo siguiente: «Tal lucha se da entre el cardenal J. Ratzinger, prefecto de la Congregación para la Doctrina de la Fe y los defensores de la Teología de la Liberación. Es por ello que Sebastián Urrutia es enviado a Europa a estudiar la manera de destruir a las "palomas" que deterioran la Iglesia en Chile y, es por eso que, en sueños, encuentra a los principales "cetreros", al "Papa (Juan Pablo II) con un teólogo alemán (J. Ratzinger) hablando tranquilamente en una de las habitaciones del Vaticano (p. 95)”.» In Pablo Berchenko, El referente histórico chileno en Nocturno de Chile de Roberto Bolańo, La memoria de la dictadura, Fernando Moreno (ed.), Paris: Ellipse, 2006, p. 17. Debemos subrayar que, como el título del artículo lo anuncia, el profesor Berchenko destaca en él los (en ocasiones no tan evidentes) referentes históricos de la novela, lo cual permite tener consciencia de la preocupación de Bolaño por «enmascarar» eventos, pero al mismo tiempo ser más sensible a la manera en que los convierte en ficción y, por lo tanto, les da un significado único y original.

42. Ibid., p. 101.

43. Ibid., p. 102, 104, 105, 106. 
ser verdaderamente formulado, lo que los señores Odeim y Oido propondrán a $\mathrm{H}$. Ibacache se circunscribe a un espacio particular, en el que se subraya tanto una como otra de las facetas del narrador: se le confía un secreto al sacerdote, pero al mismo tiempo se solicita al hombre de letras transmitir su conocimiento «a unos caballeros». De este modo, el conocimiento de H.Ibacache, termina convertido en valor de cambio pues se le asigna un precio específico (los honorarios a los que hace alusión el señor Odeim). El precio específico que se le entregará al poeta y crítico somete su voluntad y compra su colaboración ${ }^{44}$. "Vender su alma al diablo" es una expresión castellana que cobra todo su sentido frente a lo que acepta el sacerdote Urrutia Lacroix y cumple el crítico H. Ibacache. Desde luego, podemos decir que aceptar una remuneración atenúa su responsabilidad -pues actúa en tanto profesional-, pero al mismo tiempo enfatiza su incapacidad (¿desinterés?) de reivindicar para su saber o conocimiento un valor distinto al pecuniario. El conocimiento no es libre ni independiente; él se encuentra determinado a quien merezca adquirirlo, en otros términos, quien tiene los medios y el poder de hacerlo.

No deja de resultar irónico, por lo demás, que se le solicite «un servicio que se realiza en la oscuridad" al mismo individuo que anteriormente comparara el trabajo de un crítico literario con un faro que ilumina, en medio de las tinieblas, el derrotero de los navíos. Sin saberlo, el señor Odeim le pide a H. Ibacache traicionar su concepción de la labor del hombre de letras y crítico, cambiar de bando, desplazarse a las regiones de las cuales siempre ha pretendido renegar. La palabra, la misma que anteriormente permitía, según su concepción, cultivar y civilizar, se convierte, gracias a una orden del supremo gobernante, en una subordinada de las armas, la violencia y el crimen. De ahí que de los labios del señor Odeim no salgan precisamente palabras sino las inmundicias más nefastas: «dijo (...) acercando su cabeza a la mía y echándome sobre la nariz una vaharada de cloaca». Si alguna duda quedaba con respecto a la inmoralidad de la propuesta, el recuerdo de $\mathrm{H}$. Ibacache se encarga, por medio de esa precisión sensorial, de caracterizar sin ambigüedades el tenor de la misión que se efectuará. Desde ese momento, el quehacer del hombre de letras conocerá una nueva expansión en el espacio social. No sólo será el dandy afanoso por conversar de lejanos poetas europeos, ni tampoco el glosador de las publicaciones de sus coetáneos, sino también el silencioso cómplice que alimentará la barbarie mediante el sometimiento y la prostitución de su saber.

El sujeto letrado se somete al poder establecido para cooperar con él, bajo pretexto de servir a la Nación (como si los valores altruistas invocados por el señor Odeim pudiesen calmar la conciencia del personaje). Dicha cooperación lo coloca por encima del dictador en tanto agente de conocimiento (él posee el conocimiento que el dictador no tiene ${ }^{45}$ ) pero se trata de una superioridad

44. Como si no fuese suficiente con esta alusión a los «honorarios» más adelante el mismo narrador recuerda la manera en que éstos se le alcanzaron cuando dice que: «el coronel Pérez Larouche (...) se encargó de entregarme un sobre que no quise abrir», Ibíd., p. 106.

45. En un momento, ambos personajes, sacerdote y dictador, salen a dar una vuelta para 
engañosa, invertida por el monopolio del poder y su ejercicio del cual disfruta Augusto Pinochet. De ahí que al final de las clases de marxismo, H. Ibacache necesite la refrendación del mismísimo general: «Le pregunté si las clases habían estado a la altura de lo que de mí se esperaba. Váyase con la conciencia tranquila, me aseguró, su trabajo ha sido perfecto» ${ }^{46}$. Aquel que llevó a la sociedad chilena a la más oscura de sus épocas es el mismo que tranquiliza a $\mathrm{H}$. Ibacache al aconsejarlo que se retire con la conciencia tranquila. Un relente de patetismo se desprende de este último intercambio entre el dictador-estudiante y el sacerdote-profesor, quien regresa a su casa para llorar desconsoladamente pero sólo un instante pues casi de inmediato se queda dormido ${ }^{47}$. La culpa y los remordimientos no parecen tener más repercusiones en $\mathrm{H}$. Ibacache que el llanto de una noche ${ }^{48}$.

Silencio, oscuridad y pestilencia. La labor civilizadora adquiere en la trayectoria de $\mathrm{H}$. Ibacache un fuerte componente de complicidad y sometimiento con respecto al poder establecido y, en la medida en que este poder es un régimen de facto, con el terror. De esa manera, lejos de reivindicar para sí una actividad intelectual desasida de la historia y su curso, como lo pretende, su trayectoria se encuentra manchada por los eventos que ensombrecieron a la sociedad representada en la novela. Es necesario añadir que Roberto Bolaño no se contenta con plantear un derrotero signado por las renuncias y la complicidad. Al contrario, les confiere al final de la novela una dimensión más abarcadora y por eso más compleja a las relaciones entre la literatura y la historia que trascienden de manera dramática el caso individual de H. Ibacache.

conversar. Entonces, H. Ibacache despliega su saber frente a su «estudiante»: «Como si fuera un mago, nada más franquear el ventanal y adentrarnos en aquel jardín encantado se encendieron las luces del parque, unas luces diseminadas aquí y allá con un gusto exquisito. Hablé entonces de El origen de la familia, la propiedad privada y el estado, escrita en solitario por Engels, y a cada explicación mía el general asentía, y de tanto en tanto me realizaba preguntas pertinentes, y a veces ambos callábamos y mirábamos la luna que vagaba sola por el espacio infinito», Ibid., p. 110.

46. Ibid., p. 113.

47. Ibid., p. 113.

48. Es revelador en este sentido lo que dice el autor, Roberto Bolańo con respecto a la culpa en el protagonista-narrador: «En Nocturno de Chile, lo que me interesaba era la falta de culpa de un sacerdote católico. La frescura admirable de alguien que por formación intelectual tenía que sentir el peso de la culpa. Yo creo que la culpa, es de las pocas cosas buenas de la religión católica. Siempre me ha parecido una entelequia seudodionisiaca la del hombre libre de culpa. En este sentido, por supuesto, estoy totalmente contra Nietzsche. Vivir sin culpa es como vivir fuera del tiempo, en un presente perpetuo, en una cárcel de soma o como se llamara esa droga que tomaban en Un mundo feliz, de Huxley. Vivir sin culpa es abolir la memoria, perpetuar la cobardía. Si yo, que fui una víctima de Pinochet, me siento culpable de sus crímenes, ¿cómo puede alguien que fue su cómplice, por acción o por omisión, no sentirse culpable?» In Andrés Braithwaite, Bolaño por si mismo: entrevistas escogidas, Santiago: Ediciones Universidad Diego Portales, 2008, p. 114. 


\section{Y DESPUÉS SE DESATA LA TORMENTA...}

Como si se tratase de un juego de espejos en el cual una imagen repite, pero al mismo tiempo tergiversa, otra sin cesar, hacia el final de la novela el lector encuentra un espacio singular que recuerda a otro ya conocido : el fundo $L \grave{a}-b a s$ de Farewell. Me refiero a la casa-salón de María Canales una mujer santiaguina letrada, de posición acomodada y que además era «simpática», «se hacía querer» y «no parecía importarle nada más que la comodidad de sus invitados»" Solvente económicamente, dueña de un carisma unánime, ella busca y procura, lo mismo que Farewell, rodearse de artistas. En su casa se habla de literatura norteamericana, se escucha música alemana y se comentan las últimas películas estrenadas en Nueva York ${ }^{50}$. En este sentido, el paralelo con Là-bas resulta una evidencia en la medida en la cual en ambos espacios se discute, en una atmósfera sofisticada de tertulia y bohemia, acerca de la producción cultural de otras latitudes. Las discusiones permitirían a los participantes reconocerse entre sus pares y, al mismo tiempo, formar parte de un círculo prestigioso y distinguido.

Con todo, decimos que evoca sin repetir pues entre uno y otro espacio existen diferencias patentes que demuestran una evolución socio-económica en el Chile representado por la novela. Así, si por un lado encontramos un lugar alejado de la ciudad, sustentado gracias a la explotación y la producción agrícolas, manejado por un terrateniente letrado y europeizante; por el otro, el lector encuentra a una mujer de sociedad cuya preeminencia, antes que nada, se debe a sus vínculos maritales con un norteamericano ${ }^{51}$ y a su capacidad manifiesta para atraer a la gente antes por su simpatía que por su inteligencia: «Le gustaba

49. Ibid., p. 126.

50. «Luego los niños desaparecían y desaparecía la empleada, que se encerraba en el cuarto contiguo a la pieza de los pequeńos, y abajo, en la amplia sala de María Canales, empezaba la fiesta, la anfitriona servía whiskys a todo el mundo, alguien ponía un disco de Debussy, un disco de Webern grabado por la Berliner Philharmoniker, al poco rato a alguien se le ocurría recitar un poema, a otro se le ocurría ponderar en voz alta las virtudes de tal o cual novela, se discutía de pintura y de danza contemporánea, se hacían corrillos, se criticaba la última obra de fulanito, se decían maravillas de la más reciente performance de menganito, se bostezaba, a veces se me acercaba un poeta joven, contrario al régimen, y se ponía a hablar de Pound y terminaba hablándome de su propio trabajo (yo siempre estaba interesado por el trabajo de los jóvenes, tuvieran la orientación política que tuvieran), la anfitriona aparecía de repente con una bandeja rebosante de empanadas, alguno se ponía a llorar, otros cantaban, a las seis de la mañana, o a las siete, cuando ya había terminado el toque de queda, todos volvíamos en una fila india vacilante hacia nuestros autos, algunos abrazados, otros medio dormidos, la mayoría felices, y luego los motores de seis o siete autos atronaban la mañana y enmudecían por unos segundos el canto de los pajarillos en el jardín, y la anfitriona nos hacía adiós con la mano desde el porche, y los autos empezaban a salir del jardín, uno de nosotros previamente se había encargado de abrir el portón de hierro, y María Canales seguía de pie en el porche hasta que el último auto trasponía los límites de su casa, los límites de su castillo hospitalario (...)", Ibid., p. 127-128.

51. «(...) estaba casada con un norteamericano llamado James Thompson, que era representante o ejecutivo de una empresa de su país que hacía poco había instalado una filial en Chile y otra en Argentina, y al que María Canales llamaba Jimmy». Ibíd., p. 126 
el arte, le gustaba hablar con pintores, con gente que hacía performances y vídeos artísticos, tal vez porque su cultura general era manifiestamente menor que la de los escritores. O eso creía ella ${ }^{2}$. Así, ya no nos encontramos frente a un individuo letrado que refrenda su herencia socio-cultural sino frente a una mujer que negocia su lugar en una sociedad menos estamental pero igualmente jerarquizada. Versión latinoamericana de una Madame de Staal-Delaunay, por dar uno de los tantos nombres de las mujeres occidentales que regentaron salones, María Canales parece menos segura que Farewell de su preeminencia y, por lo tanto, más dispuesta a ganársela mediante los favores y los servicios hechos a quienes forman parte de su corte "americanizante».

El relato «autobiográfico» de Urrutia Lacroix aleja y acerca alternativamente ambos espacios, ubicados en las antípodas uno del otro ${ }^{53}$ pero al mismo tiempo reunidos por la trayectoria del sacerdote crítico. Una trayectoria que no deja de parecer oportunista pues, pese a los cambios producidos en el campo letrado, sometido a una particular modernización, H.Ibacahe es el único crítico literario que, indolente pero férreamente, se mantiene vigente $e^{54}$. Como si se tratase de una relación inversamente proporcional, el ascenso del salón de María Canales, significa el eclipse del Là-bas de Farewell: "Qué lejos estaba Farewell de todo. (...) La verdad es que ya no se podía hablar con Farewell. A veces me le quedaba mirando y pensaba: viejo chismoso, viejo alcahuete, viejo borracho, así pasa la gloria del mundo» ${ }^{55}$. De entre los escombros del mundo que alguna vez fue encarnado por $L \grave{a}$-bas, se levanta $\mathrm{H}$. Ibacache para marcar la continuidad y al mismo tiempo formular el cambio en el salón de María Canales. ¿Qué gana o refrenda el crítico y sacerdote con esta actitud? ¿De qué manera y a qué precio se inserta en esta nueva economía de valores culturales?

La lectura minuciosa del espacio social en Nocturno de Chile resulta reveladora de los términos que se negocian tanto de un lado (H. Ibacache) como del otro (María Canales). Recordemos, en ese sentido, lo que afirma Bourdieu en Les règles de l'art cuando analiza el caso de L'éducation sentimentale:

52. Ibid., p. 124-126.

53. Antípodas geográficas : Santiago y la provincia, antípodas textuales : comienzo y fin del texto.

54. De hecho, el mismo Urrutia Lacroix señala el antagonismo, justificado en el juicio estético, que separa a María Canales de Farewell cuando recuerda que le alcanzó a su mentor uno de los cuentos escritos por ella : «El cuento no era malo, pero distaba mucho de ser bueno. Era una medianía voluntariosa, como su propia autora. Cuando se lo enseñé a Farewell, que por aquel tiempo aún vivía, pero que nunca fue a una velada literaria a casa de María Canales, mayormente porque Farewell ya casi no salía de su casa y apenas hablaba o sólo hablaba con las viejucas amigas suyas, me dijo, tras leer unas pocas líneas que se trataba de un texto espantoso, indigno incluso de recibir un premio en Bolivia (...)». Ibíd., p. 130. A la decadencia física de Farewell, a la que hace alusión $\mathrm{H}$. Ibacache, se le añade un elemento aún más perentorio: su pérdida del uso de la palabra. Una pérdida que, por la ambigüedad del enunciado, se puede explicar por razones físicas pero también por pérdida de su prestigio social. Sin palabras ya no puede dirigir su cenáculo que, por lo demás, se ve reducido a un grupo de ancianas («viejucas» dice de manera peyorativa el narrador, insistiendo de esa manera sobre la temática de la decadencia).

55. Ibid., p. 134. 
Les contraintes inhérentes à l'appartenance au champ du pouvoir s'exercent aussi sur le champ littéraire à la faveur des échanges qui sétablissent entre les puissants, pour la plupart des parvenus en quête de légitimité, et les plus conformistes ou les plus consacrés des écrivains, notamment au travers de l'univers subtilement hiérarchisé des salons ${ }^{56}$.

Si lo que le importa a H. Ibacache, como ya lo hemos visto, es el prestigio de conocer y estrechar las manos de escritores reconocidos o de aspirantes talentosos para después enumerar, lleno de vanidad, las personas a las frecuentó, entonces el salón de María Canales es el mejor lugar del momento para hacerlo. Hasta él acuden un "poeta desesperado», una "novelista feminista», un "pintor de vanguardia» $y$, de tanto en tanto, la anfitriona misma, María Canales ${ }^{57}$ : todos los asistentes de la tertulia se aproximan ritualmente a $\mathrm{H}$. Ibacache para el besamanos áulico con el cual formar parte de su séquito. Es necesario resaltar que incluso una separación espacial se opera en el mismo salón a favor de H. Ibacache: «en sus ventanas yo solía sentarme en un rincón», dice primero para después completar «a veces María Canales entraba en mi corrillo. ¡Siempre simpática! ¡Siempre dispuesta a complacer mis más nimios deseos! ${ }^{58}$. Bajo el influjo de $\mathrm{H}$. Ibacache, el mismo salón de María Canales se desdobla en dos territorios: aquel en el cual la dueńa de la casa ejerce su autoridad real y aquel otro en el cual el sacerdote escritor reivindica un territorio liberado para sí mismo y en el cual la mismísima anfitriona debe someterse a sus caprichos. La denominación de «rincón» peca, por lo tanto, de falsa modestia pues en aquel "centro" intelectual y artístico de Santiago que es la casa de María Canales el crítico H. Ibacache ocupa indiscutiblemente el lugar más importante, de mayor prestancia.

Sin embargo, H. Ibacache se encuentra en el salón de una artista a quien denigra. Así, por ejemplo, cuando se refiere a un cuento escrito por ella afirma que «el cuento no era malo, pero distaba mucho de ser bueno. Era una medianía voluntariosa como su propia autora " ${ }^{59}$. Más adelante explicita lo que considera es falta de entendimiento de su parte: «Pero yo creo que apenas comprendía mis palabras, mi discurso. Hacía como que comprendía, pero qué iba a comprender». Finalmente, la califica categóricamente de «boba sufriente» ${ }^{60}$. El ascendiente que capitaliza $\mathrm{H}$. Ibacache frente a los demás miembros del salón y la misma anfitriona parece ser, siguiendo la cita de Pierre Bourdieu, el valor de cambio que utiliza para elevar a los demás, contertulios y anfitriona, hacia regiones de las cuales se encontrarían excluidos de no ser por los oficios del sacerdote-crítico. Esa advenediza (parvenue para retomar la expresividad de la palabra francesa que utiliza Bourdieu) que es María Canales invierte su brillo social y su riqueza económica para poder acercarse a la imagen que para sí misma ambiciona la de una mujer letrada.

56. Pierre Bourdieu, op. cit., p. 89.

57. Ibid., p. 131.

58. Ibid., p. 133.

59. Ibid., p. 130

60. Ibid., p. 133. 
Hasta aquí tenemos una fascinante representación del mundo literario con su inalienable pasión por el arte, por un lado, pero su auténtica venalidad, por otro: el camino a la tierra prometida de la literatura está empedrado de renuncias e hipocresías. Sin embargo, Roberto Bolaño da un paso más al darle, hacia el final de la novela, un valor adicional a esa «legitimidad» que se otorgan recíprocamente $\mathrm{H}$. Ibacache y María Canales. Se trata de un elemento, que no aparece de manera inmediata sino que el narrador va comunicando paso a paso, como si su enunciación no pudiese hacerse sino multiplicando rodeos. Cuando muchos años después se descubren las actividades secretas que se realizaron en la casa de María Canales, adquiere su justo y lamentable valor la actividad del salón literario: «Y luego llegó la democracia, el momento en que todos los chilenos debíamos reconciliarnos entre nosotros, y entonces se supo que Jimmy Thompson (el marido de María Canales) había sido uno de los principales agentes de la DINA y que usaba su casa como centro de interrogatorios ${ }^{61}$. Mientras que en la planta baja todos intercambian ideas y reflexiones en torno al arte, metros más abajo, en los subsuelos, las personas agonizan por culpa de la violencia asesina que el poder de facto ejerce sobre ellas. Una y otra actividad, la pública y la clandestina, encuentran, a posteriori, una particular y espeluznante complementariedad.

Una vez hecha pública esa verdad a media voz los artistas chilenos se vieron culpabilizados por su silencio cómplice: todos sabían lo que ocurría en los sótanos sin atreverse a hacerlo público y, de ese modo, salvar a los anónimos torturados $^{62}$. En lugar de ello, prefirieron guardar las apariencias y hacer como si nada hubiese ocurrido o, en última instancia, darle rienda suelta al rumor: «Y meses después, o tal vez años después, otro habitual de las veladas me contó la misma historia. Y luego otro y luego otro y otro más»" ${ }^{63}$. Entre el silencio y el rumor, la palabra no puede tener ningún peso político pues no es pública; al contrario, ella se mantiene en los márgenes de la oscuridad (ya bastante connotada a estas alturas del texto). Los sujetos letrados que por su lugar social, como lo reivindica en numerosas ocasiones $\mathrm{H}$. Ibacache, están llamados a iluminar a los demás, le dan la espalda a su misión. Si antes el sacerdote crítico terminó él mismo renunciando a sus ideales civilizadores, frente a la propuesta de los señores Odeim y Oido, ahora descubrimos que todos los artistas y hombres de letras chilenos actuaron como él. La legitimidad que los escritores le entregan al horror, al horror no tal y como lo entendió en Là-bas el joven Urrutia Lacroix (consecuencia de un rechazo racial y clasista), sino al horror moral, aquel capaz de las peores vejaciones, es la verdad a la cual se llega al final. Una verdad que es patente para el caso de la dictadura chilena y que también

61. Ibid., p. 141.

62. El silencio de los artistas es representado en los gestos del personaje que descubrió la actividad oculta de los sótanos : «(...) y el dramaturgo o el actor había cerrado la puerta sigilosamente, procurando no despertar al pobre hombre que reparaba en el sueño su dolor, y había desandado el camino y vuelto a la fiesta o tertulia literaria, la soirée de María Canales y no había dicho nada». Ibid., p. 140.

63. Ibid., p. 141. 
se ramifica sin concesiones por todas partes, como lo revela el encuentro final entre una alicaída María Canales y H. Ibacache:

¿Quiere ver el sótano? Me levanté, di unos pasos por la sala en donde antes se reunían los escritores de mi patria, los artistas, los trabajadores de la cultura y dije no con la cabeza. Me voy María me tengo que ir, le dije. Ella se rió con una fuerza incontenible. Pero tal vez fue sólo mi imaginación. Cuando estuvimos en el porche (comenzaba lentamente a anochecer), me tomó la mano, como si de improviso hubiera sentido miedo a quedarse sola en aquella casa condenada. Apreté su mano y le sugerí que rezara. Me hallaba muy cansado y mis palabras fueron dichas sin convicción. No puedo rezar más de lo que rezo. Inténtelo, María, inténtelo. (...) Luego miró a su alrededor (...) y dijo que así se hacía la literatura en Chile. Yo incliné la cabeza y me marché. Mientras conducía de vuelta a Santiago, pensé en sus palabras. Así se hace la literatura en Chile, pero no sólo en Chile, también en Argentina y en México, en Guatemala y en Uruguay, y en Espańa y en Francia y en Alemania, y en la verde Inglaterra y en la alegre Italia. Así se hace la literatura. $\mathrm{O}$ lo que nosotros, para no caer en el vertedero llamamos literatura ${ }^{64}$.

¿Qué sentido darle a la barbarie de la cual participan los hombres letrados? Lo mejor, frente a los ojos de los demás es escamotearla, procurar olvidarla para conservar intacta, de ese modo, una imagen social: «María Canales se quedó sola. Todos sus amigos, todos los que habían acudido gustosos a sus veladas literarias, le dieron la espalda ${ }^{65}$. Pero, hasta cierto punto, $\mathrm{H}$. Ibacache no lo hace pues, a diferencia de los demás, acude voluntariamente a la casa de la antigua dueña de salón, donde constata el abandono y la degradación del espacio y también de la misma María Canales. La ceguera homérica del crítico literario de la cual se hizo mención en casa de Farewell, adquiere un significado inaudito pues esta vez, en lugar de alienarlo de la realidad, o reivindicar su atemporalidad clásica, le permite una particular clarividencia frente a los hechos históricos. Espectador privilegiado de su época, H. Ibacache será la única persona que haya visto o presenciado todos los horrores a los que, por acto u omisión, se exponen artistas y hombres de letras, tomando también parte en ellos. Así, si bien decide una vez más darle la espalda, no ver el sótano («Me voy María me tengo que ir»), esta vez es diferente pues ya no se trata del joven indolente que comenzaba su carrera literaria sino de un individuo experimentado, enfrentado, a la verdad que no quiso o no trató de descubrir: «Así se hace la literatura. O lo que nosotros, para no car en el vertedero llamamos literatura».

$\mathrm{Si}$, como lo dijimos en la introducción, Urrutia Lacroix decide escribir bajo pretexto de enfrentarse a los improperios y maledicencias del joven envejecido bajo otro signo es cómo termina su relato. Después de haber dado cuenta de su biografía, de su prestigio y lugar preponderante en la escena cultural chilena, así como manifestado una concepción estetizante del quehacer literario, su pretendida imagen le cede lugar a sus actos, por lo tanto, a la renuncia y la complicidad frente a los abusos e injusticias. Proyecto de hagiografía que

64. Ibid., p. 146-147.

65. Ibid., p. 142. 
termina convertido en testimonio de un criminal, la escritura desvela el horror para, en un doble movimiento, descubrir su impotencia pero también su sometimiento. De ahí ese final - del texto, de la confesión, de la vida- en el que la escritura se cierra con el advenimiento del apocalipsis: «Y después se desata la tormenta de mierda». Las palabras no parecen bastar para penetrar en el corazón de las sombras; ellas son una tenue tregua antes del fin que, en toda su crudeza, anuncia la coprolalia como única solución posible para quien escribe pretendiendo darle la espalda a la historia.

\section{Conclusiones}

Pese a su brevedad, o gracias a ella, Nocturno de Chile es acaso la novela de Roberto Bolaño en la que se plantean de la manera más densa y compleja las ambigüedades y paradojas relacionadas con el quehacer intelectual y artístico, por un lado, y los poderes sociales económicos y políticos, por el otro. Así, lejos de mostrar una relación clara (aunque tal vez maniquea), de resistencia y combate, por ejemplo, entre el poder establecido y los individuos letrados, en Nocturno de Chile se representa y tergiversa una compleja red de relaciones que van de la sumisión cortesana a la complicidad por silencio y omisión. En la trayectoria del narrador-protagonista, Sebastián Urrutia Lacroix o H. Ibacache se figura el derrotero de todo un grupo y una época determinados de la segunda mitad del siglo XX. De ese modo, el sacerdote y crítico literario se convierte en el símbolo de las dobleces, las traiciones y, sobre todo, los conflictos del campo literario chileno, convertido en metáfora, desgarradora y corrosiva, de lo que es en verdad hacer literatura: un ejercicio vinculado, de un modo u otro, a la barbarie, el horror y la violencia de los que pretende renegar.

Sin concesiones, mordaz y amarga, la ficción de Roberto Bolaño propone un retrato sombrío de la sociedad y la literatura, donde nadie es inocente, pues esta última obedece a imperativos que no tienen nada que ver con el «arte por el arte», las «torres de marfil» o las «musas poéticas». Sin embargo, al hacer esto, produce el efecto radicalmente opuesto pues actualiza esa capacidad que posee la literatura para iluminar los intersticios, las zonas de sombra y tinieblas, de los individuos y las sociedades interrogando así al lector de manera descarnada pero también purificadora. Siguiendo en este punto a Georges Bataille, precisamente por abismarnos la literatura en el Mal, nosotros los lectores podemos alcanzar un acercamiento crítico a nuestra realidad donde abundan los $\mathrm{H}$. Ibacache pero también existen los Roberto Bolańo, escritores que, en equilibrio vertiginoso, rozan los límites del silencio y la palabra. silencio y la palabra ${ }^{66}$.

66. Así lo formula Georges Bataille en su introducción al ensayo La littérature et le mal: La littérature est communication. La communication commande la loyauté : la morale rigoureuse est donnée dans cette vue à partir de complicités dans la connaissance du Mal, qui fondent la communication intense. / La littérature n'est pas innocente, et, coupable, devait à la fin s'avouer telle. In Georges Bataille, La littérature et le mal, in CEuvres complètes IX, Paris : Gallimard, 1979, p. 171-172. 


\section{Bibliografía}

\section{1) Corpus:}

Bolaño Roberto, Nocturno de Chile, Barcelona : Anagrama, 2000, p. 150 p.

\section{2) Secundaria:}

Bakhtine Mikhaïl, L'ouvre de François Rabelais et la culture populaire au Moyen Âge et sous la Renaissance, Paris, Gallimard, 1970, 471 p.

Bataille Georges, La littérature et le mal, in Euvres complètes IX, Paris, Gallimard, 1979, p. 168-316.

Benmiloud Karim y Raphaël Estève (eds.), Les astres noirs de Roberto Bolaño, Bordeaux, Presses Universitaires de Bordeaux, 2007, 231 p.

Benmiloud Karim, "Odeim y Oido en Nocturno de Chile de Roberto Bolaño ", Aisthesis, 48, 2010, p. 229-243.

Bourdieu Pierre, Les règles de l'art: genèse et structure du champ littéraire, Paris, Seuil, 1998, 567 p.

Braithwaite Andrés, Bolaño por si mismo: entrevistas escogidas, Santiago, Ediciones Universidad Diego Portales, 2008, 145 p.

Dupriez Bernard, Gradus, les procédés littéraires, Paris, 10/18, 1984, 535 p.

Herralde Jorge, Para Roberto Bolaño, Santiago, Catalonia, 2005, 95 p.

Moreno Fernando (ed.), La memoria de la dictadura, Paris, Ellipses, 2006, 384 p.

Moreno Fernando (ed.), Roberto Bolaño. Una literatura infinita, Poitiers, Centre de Recherches Latino-américaines, Archivos, 211 p.

Paz Soldan Edmundo y Gustavo Faverón (eds.), Bolaño salvaje, Barcelona, Candaya, 2008, 502 p.

Weisgerber Jean, L'espace romanesque, Lausanne, Éditions l'Âge d'homme, 1978, 265 p. 